\title{
Head and Neck Cancer cN3 TNM Finding v8
}

National Cancer Institute

\section{Source}

National Cancer Institute. Head and Neck Cancer cN3 TNM Finding v8. NCI Thesaurus.

Code C132639.

Head and neck cancer with metastasis in a lymph node larger than $6 \mathrm{~cm}$ in greatest

dimension and ENE(-); or metastases in a single ipsilateral lymph node $\mathrm{ENE}(+)$; or

metastases in multiple ipsilateral, contralateral, or bilateral lymph nodes, any with ENE(+).

(from AJCC 8th Ed.) 